\title{
Generations and Emotional Intelligence A Pilot Study
}

\section{Renáta Machová ${ }^{1}$, Tibor Zsigmond ${ }^{\mathbf{1}}$, Kornélia Lazányi ${ }^{2}$, Veronika Krepszová ${ }^{1}$}

${ }^{1}$ J. Selye University, Faculty of Economics, Department of Management, Hradná st. 21, 94501 Komárno, Slovakia

machovar@ujs.sk, zsigmondt@ujs.sk, krepszovav@ujs.sk

2 Óbuda University, Keleti Faculty of Business and Management, Dean Office, Tavaszmező u. 17, 1084 Budapest, Hungary

lazanyi.kornelia@kgk.uni-obuda.hu

Abstract: Emotional intelligence is at the heart of our research. Our aim was to examine the differences that exist between generations, based on the views of their representatives. In the theoretical portion we dealt with defining emotional intelligence and presenting it from the leaders' aspect. Finally, each generation is introduced. In our paper we set up 2 hypotheses, which are cross-tabulated and / or analyzed with the help of related statistical methods. In the end, both our hypotheses proved to be true. This article contains 2 figures and 2 tables. Our paper ends with a section on conclusions, in which we summarize our research, results and outline our findings.

Keywords: emotional intelligence; generations; workplace

\section{Introduction}

This article is about emotional intelligence. We chose this topic in order to demonstrate the presence of emotional intelligence in the $21^{\text {st }}$ Century. Emotional intelligence plays an important role in everyday life. We do not notice it, but our emotions determine our actions. It also affects our personality and personal relationships. That is why we would like to show how this is present at the workplaces of each age group. A job is the place where we spend most of our time, and where we meet and work with many people every day. It is important to get along well with others and that our emotions do not adversely affect our relationships or hinder our work.

In the theoretical part we introduced the concept of emotional intelligence. Within this, we introduced the individual points of view and then we approached the topic 
from the perspective of the leaders. Finally, we introduced the individual generations, respectively their characteristics.

In the practical part, we examined the relationship between emotional intelligence and belonging to an age group. The research was carried out with the help of a questionnaire, which was transmitted by the snowball sampling method. Respondents were grouped by generation, and their responses were summed up and compared. For comparison, we used diagrams, which were explained below, and finally conclusions were drawn. Our goal with this method of analysis was to demonstrate emotional intelligence and generational differences in the workplace.

\section{Theoretical Background}

Emotional intelligence is present in every person's life and in every area of our existence. It influences our own lives, our decisions, and at the same time helps to establish and maintain relationships with other people. With respect to ourselves, it helps us draw conclusions from a particular event or control our emotions in a given situation and make the necessary and appropriate decisions based on it. Emotional intelligence is a part of social relationships, even as it helps to build human relationships, to recognize the emotions of others, and to put ourselves in the role of the person and thus outline the processes that can take place in that person.

\subsection{Emotional Intelligence}

The word emotion comes from the Latin word "motore", it means to move. The word "e" indicates that it is moving. So emotions go hand in hand with the urge to act. This has been retained by evolution [10]. Salovey and Mayer [28] define emotional intelligence as "the subset of social intelligence that involves the ability to monitor one's own and others' feelings and emotions, to discriminate among them and to use this information to guide one's thinking and actions." [19] This view was used by Schutte et al. [29] while developing a valid measurement for emotional intelligence. According to Neale et al. [24] our emotions influence the way we act, make decisions, or judgments, so they affect everything we do. Joseph and Newman [14] distinguished two interpretations of the EI: "1) as set of specific competencies for recognizing and controlling individual emotions and 2) as a grab bag of constructs that contribute to job performance but are not redundant with cognitive ability." Emotions provide individuals with essential regulation and orientation in their function, which aims to facilitate adaptation to certain conditions [37]. Emotional intelligence is increasingly present in everyday life. It can be found in social contacts such as human relationships and leadership activities. It is essential for controlling and managing the emotions of ourselves, 
others, and groups. Emotions have a big impact on the quality of relationships within a business. This can only be formed and developed by internal factors [26]. Emotional intelligence (EI) is today a vital concept in the field of psychology. It extends its influence into the world of work and, through it, into each workplace, thus giving rise to a global concept. The EI can partly intervene in business problems, as it affects executives. Therefore, companies and enterprises treat this issue as a key issue and consider it to be a basic operational factor of an organization, even though it is not a sort of a physical concept [6]. Developing emotional intelligence brings benefits and enhances performance. This can help you communicate more effectively with others, have a better personal connection, have a stronger empathic ability, have better career prospects, and have more confidence in managing change. In addition, it contributes to several other things e.g., more respect for others, less power play in the workplace, less stress, more confident and positive thinking and increased creativity [24]. Workplaces are undergoing change. They not only judge individuals how smart they are, i.e. how developed their cognitive intelligence is, but also by how they treat others and themselves. This standard is used to judge who to employ, who to promote and who to send. According to [9] the new standard takes the appropriate intellectual ability and expertise as basic, and instead focuses on personal qualities such as initiative, empathy, adaptability and persuasion [1] [32].

The main factor influencing emotional intelligence is, according to researchers, the environment itself, as it often has a profound effect on an individual's level of emotional development. Environmental influences can guarantee the development of emotional intelligence, but the opposite is also true, it can also hinder it. For example, the mood in the workplace significantly determines the emotional intelligence of the manager or subordinates. Environmental impulses make it difficult to enhance emotional intelligence. The most influential effect for people is their own cultural environment, which has a great influence on the development and formation of emotional intelligence. One of the most important phenomena today is the examination of the importance of organizational culture. Organizational culture provides an opportunity to promote workplace results and create a positive workplace atmosphere. The goal of organizational culture is to create internal integrity, support external adjustment, and reduce the uncertainty of organizational members [3]. Conflict management appears as a factor that directly or indirectly influences the development of organizational culture, which is closely related to a person's emotional intelligence. Its purpose is to develop a method that enables organizational conflicts to be handled in situations where two people's efforts are incompatible. Conflict management is influenced by the general characteristics of the individual, the emotional state of the participants in the given situation, the organizational atmosphere and the relationship between the participants in the confrontation. In addition, perception of individuals' intentions and motivations also have an impact. Smart and successful individuals seek problem solving and collaboration, while the unsuccessful ones seek ruler type solutions [3] [18] [22] [32]. 
Emotional intelligence is increasingly important in human management. EQ is not equal to personality, it is a combination of countless abilities and competencies that influence behavior, radiance and personal style. This type of intelligence plays an important role in the workplace as it plays a decisive role in behaving in a communication situation and in dealing with people. Emotional intelligence is the closest to empathy. The latter allows us to recognize the emotions of others and it enables us to gauge their thinking and behavior. In emotional management, control of mood and behavior is essential in stressful, complex situations. EQ contributes to expressing our appreciation to others, and it also lays the foundation for effective communication. While IQ helps in individual task solving, EQ plays an important role in the development of employee relationships. Individuals with a higher level of emotional intelligence can better manage their own feelings and thus be better at achieving their goals. According to research, those with lower EQs have done worse work than sales teams that have done better in this area. In the world of work, it is extremely important to motivate others. In a leadership role, it is essential for someone to know and influence the subordinates' thinking [3] [32] [41].

\subsection{Aspects of Emotional Intelligence}

The key to success is to be aware of emotions, learn how to control and manage them, and furthermore understand the others' feelings. Therefore, emotional intelligence crosses two perspectives. One is the self-knowledge of an individual in order to understand his or her goals, motivations, behaviors, and reactions. The second step is to understand people's feelings and behaviors. These are also called intrapersonal and interpersonal skills. We as individuals are centered in the intrapersonal intelligence. It is the ability to understand what is happening in us and to act accordingly. Interpersonal intelligence is related to the people around us. That is being aware of how we intercept and understand the actions and emotions of others [24].

Emotional intelligence can be developed in all areas, i.e. all attitudes can be changed. Research has shown that it takes at least 21 days to change an attitude. A real change requires elements of the KASH model. These include knowledge (K), attitude (A), skills (S) and habits (H). Most trainings are almost exclusively focused on knowledge transfer and skill development, so they are intended to shape the thinking brain. However, sustainable change can be achieved by changing behavior and habits as well, by which the emotional brain is concerned [24]. Understanding and controlling the emotional side of the brain is required to improve emotional intelligence and decision making. This can be done by developing five key skills. If we are able to calm down and relieve stress quickly, will help us to stay balanced, focus on tasks no matter what challenges we face or how stressful we are. Emotional awareness is the ability to relate to our emotions. Without emotional awareness, we cannot fully understand our own motivations 
and needs or communicate effectively with others. A good communicator needs more than just verbal skills. This is non-verbal communication. You need to keep the attention of others and build a confidential relationship with others. You should also be able to read and respond accurately to non-verbal signals that other people send. Humor and the use of toys to tackle challenges is also important. Humor, laughter, and play are natural remedies to ease the burden. Positive conflict resolution and confidence building skills support the previous four emotional intelligence skills. Therefore, is very important to handle stress, to stay emotionally aware, to communicate not just verbally, to use humor and play, and by all these you will be better able to handle emotionally charged situations, and to recognize and eliminate many problems before they spread [8].

Goleman [10] first divides emotional intelligence into two parts. In his view, personal skills are the responsibility for treating ourselves, while social competencies are responsible for managing social relationships. He further breaks down these two skills, providing the right foundation for developing emotional intelligence. So, based on these principles, the first step is to measure the work. It has to be focused on skills that help the employee perform well. The next step is to assess the individual, which involves examining the weaknesses and strengths of the person and then developing them. Feedback is important, as the personal characteristics assessed are emotionally charged, so special attention should be paid to their formulation. The next is the assessing the needs for change. It is important to observe the individual's aspiration for development and their attitude to change. Motives, that is, motivation that helps individuals to complete successful learning processes. The more you strive for personal development, the better you will achieve it. It is necessary to set an example, set role models for individuals. These role models possess the ability to develop and stand as a good example. Encouraging participants and supporting the organizational environment also greatly contribute to the successful acquisition of skills. Providing affirmative feedback is also helpful as individuals need validation and recognition. They need to feel that their efforts for change are not in vain. Finally, evaluation should not be forgotten. It is necessary to evaluate development and make sure that changes are permanent [3] [38].

Emotional intelligence plays an important role in an organization, because an organization must select its employees based on their emotional intelligence and organize the level of growth of employee training. People with high levels of emotional intelligence are more balanced and stable than people with lower levels of emotional intelligence. This intelligence is linked to the various relationships within the organization. It also influences leadership, work balance, conflict management, and stress management. In addition, it also reduces employee turnover. It has a great impact on the behavior of employees at work. It enhances employee tolerance and makes them feel good with their co-workers. Personal or workplace skills contribute about $20 \%$ to personal success in life, while emotional intelligence contributes to it $80 \%$. It is easier to train someone in the technical part 
of their job than to develop their intellectual intelligence. There is no emotional skill at a young age. And, there is also a tendency according to which it takes more dedication to acquire technical skills, leaving very little time and opportunity for social skills or emotional intelligence. Understanding emotions is very important in an organization for success and humanity [7] [24] [27].

\subsection{Emotional Intelligence in Leadership}

The natural way of a leadership is one that is based on emotional intelligence. An advanced personality is the basis of an effective leadership. Development of emotional intelligence is an essential task of leadership training. A certain level of intelligence - the general intellectual ability - is essential for the leader, because the knowledge acquired is rapidly obsolete today, and only the intelligent person can see through the complex mesh of problems [11]. A person with a high EQ is ideal for leadership, because it includes skills such as controlling the impulse, controlling impatience, controlling the mood, preventing frustration, suppressing thinking, developing empathy and hope [2]. The most important qualities of a leader are being able to know and control one's own spiritual phenomena and to be able to establish contacts. According to Goleman [11], in the face of an increasingly fierce competition in a globalized marketplace, the ever-changing demands of increasingly high-quality customers in a hierarchical organization cannot be met by management alone. Therefore, it is not disputed that an emotionally advanced leader is needed. It is the primary task for leaders to make sure that those who are under leadership feel comfortable. Therefore, management is primarily an emotional enterprise. The emotionally intelligent leadership style influences how the organization works. There are six leadership styles with emotional intelligence that can produce both positive and negative effects [3] [21] [23] [41].

Leaders with a vision are compassionate, have a high level of self-confidence and are often initiators of change. Affiliate leaders are also compassionate, capable of networking and handling conflict well. The democratic leader supports collaboration and teamwork, communicates confidently, and yet is often an excellent audience. The counsellor leader is emotionally conscious, compassionate, and able to recognize and utilize the strengths of others. The coercive leader builds on his/her own position of power, instructs others to pursue his/her own intentions, and has no compassion. A results-oriented leader sets high standards that he or she follows. Proactive and highly performance-centered people tend to control or criticize those who cannot achieve their own high standards and do not support their development [3] [12] [13] [21].

The basic and most important dimension of leadership is influencing emotions, which is a natural part of leadership. It is the leader who is expected to give encouragement and guidance, and thus the individual who controls the emotions 
of the community. Its role is to manage collective emotions in a positive direction and to eliminate the blocking impulse of wrathful moods. The natural leaders do not confine themselves only to have the work done by subordinates. Subordinates also expect emotional support and compassion from the leader, which is an emotional relationship based on support. If the superiors generate optimistic emotions, then everyone gives the best of their knowledge and being. This situation is called resonance. When a manager evokes negative emotions, it results in dissonance and dismantles the emotional basis that motivates the employee to perform. The groups mostly consider the emotional reaction of their leader to be the determining factor. So the leader sets up emotional norms. If the designated leader does not have enough emotional intelligence, the group will not consider him / her to be a credible leader and will therefore start to trust another manager. This person becomes the actual leader. Another style is represented by the resonant leader. He /she is the one who attunes him/herself to the subordinates' negative feelings and is able to turn them to be rather optimistic. He/she speaks honestly and convincingly. As a result, the workgroup takes on the enthusiasm and the creativity of their leader. The outburst of anger and the fear of indifference are the characteristics of a dissonant leader. Unfortunately, this is not an uncommon phenomenon in the workplace [11] [17] [21].

Coaching is the most powerful method of communication. The proper method applied effectively is able to raise awareness. It helps to improve people's performance, which improves the productivity of the group and the organization. The essence of coaching is to develop the individual's abilities in a positive way and manages to show the most of them. It gets the best out of individuals. The goal of coaching is to develop awareness and responsibility. One should not be mistaken coaching for advising. For example, telling someone what to do is not considered as coaching. During this process, we do not provide any advice and ready solutions. Nor can it be confused with mentoring, personal counselling, professional counselling or training [24]. The Coach-ee, the subject of the coaching, needs knowledge that cannot be solved by taking over the coach's own knowledge. The task is to get the necessary knowledge and bring out the hidden skills with the help of the coach [39]. People need to see not their performance but their ability [39].

Coaching can be applied in areas such as employee motivation, problem solving, team building, teamwork, training, planning and evaluation, task performance, praise and evaluation, managing human relationships, delegating, delegating, and distributing tasks [39].

Employees of an emotionally intelligent organization are productive, motivated and effective. They are committed to their goals. In many organizations, work is done in teams. The emotional intelligence exhibited by team members is crucial to team performance. This emotional intelligence helps team members to unite and be effective in operations. They are able to work together most effectively and 
bring better results to the organization as a whole. A team that does not show signs of emotional intelligence cannot operate successfully.

Team members have the opportunity to get to know each other before starting work, this is team building. In case of negative behavior, the cause should be identified and corrective action taken. Decisions must be made on the basis of the views of all team members. All members should be supported in their activities. If any problem arises, the focus should be on solving the problem, not troubleshooting [2]. Teambuilding is an ongoing process that assists the team. Not only do team members share their expectations for group assignments, they also trust and support each other and respect the personality and mindset of other individuals. The role of a Teambuilder is to lead the team towards cohesion. Empowering teams and employees allows people to make decisions about their work. Good team-building skills can bring employees together for a common goal and create greater productivity gains. Thus, it is the responsibility of the Teambuilder to ensure that all team members participate in the mission of the companies for which teambuilding is very important [15] [17] [41].

\subsection{Generations}

Today, there are six generation groups in the world, which are considered to be six distinctly different groups of people. We can say that these generations love something else, have a different lifestyle and have different qualities. This characterization is not entirely true as they share some common impulses, experiences, decades of living together, have same acquaintances, and group problems. They differ in a sense, that these problems were not experienced by them in the same way. Generation groups can also be differentiated in the workplace as their work is done in a different way. Before the $21^{\text {st }}$ Century, there was a widening gap in the workplace between generations of active workers. The change is justified by the fact that industrial society has been gradually replaced by the information society and later by the knowledge society, which has completely redefined the way people communicate. The Internet has simplified the process of obtaining information, but it has changed the way people interact and generational conflicts have appeared, since the information society has created a virtual society. Newer generations have already acclimatized to this virtual society, so they move more confidently here than in reality. As a result of this impulse, however, older generations often feel excluded from the new world. The six generations are divided and demarcated as follows: Veteran generation 19251945, Baby Boom generation 1946-1964, X generation 1965-1979, Y generation 1980-1994, Z generation 1995-2010, Alpha generation after 2010. However, only the characteristics of the generations we are investigating are described below [4] [5] [16] [33] [40]. 
Members of the Baby Boom generation were already in a more relaxed socioeconomic situation than their parents, but even more than their children. Work had a predetermined working time of when to start and finish. They were in good contact with their colleagues and talked to each other and therefore knew each other well. Their privacy was not ensnared by workplace expectations. The amount of work was determined. They knew the boss personally, had a possible or partial human contact with him, therefore was not just an unknown one. This is the last generation where hierarchy defined the principle of operation. Changes have begun with this age group. A consumer society has evolved, and Monday night slideshow watching has taken the place over family conversations. Technical devices, cars, TVs, washing machines, refrigerators have appeared. More and more things helped the baby boomers' lives, dropping into a world they were not prepared for. The world continued to expand, with television being broadcast daily and expanding with more channels. They wanted to meet the expectations of the West, so they rushed and worked more and more. And their children experienced that their parents were doing everything for them, but the price of that was that their parents were less at home. When they got home, they were anxious and full of doubts [16] [33] [35] [40].

Generation $\mathrm{X}$ is already part of the explosion of information technology. Its members were present when the computer took over the place of typewriters, but they still loved to write letters by hand and speak on the phone as in e-mail. They had less and less time for old chat meetings. Generation X worked a lot because it had to earn money incessantly, with the result that it rarely had fun. The majority of those in the workplace adapted to change and shaped their lives accordingly. The rush, the profit and loss accounts and the bonuses were strong constraints on their lives. As a result, the time spent on rest and relaxation decreased [35]. Anxiety became a part of their life and they had to deal with it constantly. There was no good-old honesty among the group of friends either. They were constantly in a hurry and rush, even on weekends, trying to bring in their back things and backlogs. Tired of falling in bed in the evenings, they got to the hamster wheel in which they spun more and more [36]. Based on these, we can say that the main motivation for this generation in their work was money and the salary. Their great mission was to create a stable existence, to create material negligence for their families and for themselves. Professional development was not one of their key goals, but those who wanted to progress, were usually pursuing a significant amount of overtime and doing extra work. Generation $\mathrm{X}$ is characterized by greater patience and work discipline than younger generations. They were able to shut down external factors and were able to handle many things at once. In their work, they relied on the intellectual knowledge they had acquired, unlike later generations, where Internet and IT played a greater role, and therefore did not feel the need to possess such profound information [5] [16] [32] [40].

Digitization was part of the life of Generation Y. They are the ones who had been most influenced by the achievements of the digital explosion and the Internet. 
Children of this age group used sophisticated technologies such as computers, video games and video players. This did not seem to cause them any effort. When new technology arrived, their parents often turned to the children to teach them [34]. From a young age, social media and a constant online presence was part of their daily lives. Members of the age group acquired almost all information on the Internet. According to their slogan "what was not found here did not even exist". Generation $\mathrm{Y}$ is the biggest challenge for companies. They are motivated by money, success, career, but they are not characterized by loyalty, reliability, adaptability and obedience. If they have the opportunity, they look for new challenges and they do not hesitate to move on. This can be explained by the fact that they had to make decisions and perform tasks early. Today's consumer society shows that it is not talent by which someone should chose, but rather potential earnings. They are not emotionally attached to their workplace. This age group has not learned that work involves effort. Thus, the new digital generations are not fully aware how much work is needed to be done to be able to buy for example the digital devices in their hands. Generation Y still has ambitions and is willing to do it for them while Generation $\mathrm{Z}$ sits at home waiting for a miracle. This age group includes self-realization, belonging somewhere, fun and public events [4] [5] [16] [31] [33] [40].

The members of the generation $\mathrm{Z}$ are still college students, but tomorrow they are the new workforce. This is the only age group born into a technologically saturated world. This is a formally educated generation. Digital technology is present in every aspect of their lives, and they have learned to use it at a young age [20]. Generation $Z$ doesn't have to learn how to handle digital devices because they already know that. For them, it is a basic training. They are the ones who are never alone, they can be online anytime and anywhere, and can talk about their thoughts, themselves and their emotions. They have two forms of identity: one is personal identity and the other is social identity. Their personal identity comes from attributes that made them unique, such as their personal characteristics, special interests, and favorite activities. In contrast, family members, friends, and neighbors contribute to their social identity [25]. The biggest difference in the age groups is that members of the $\mathrm{Z}$ generation become adults later, despite the fact that they are mentally more mature than their age. However, smart and intelligent they may seem, emotionally it is almost impossible for them to process violent or aggressive information. A major component of early maturity is the extent of aggression seen on screen. Young people today stay at home with their parents, start to work and set up their own family later. [4] [5] [33] [36]. 


\section{Aims and Methodology}

We decided to divide the respondents into four main groups based on generations: Baby Boom, Generation X, Generation Y and Generation Z. In addition, there are two generations, the Veteran and the Alpha, but these two generations have not been dealt with in the research because the "veterans" are likely no longer working, while members of the latter group are not yet working. We wanted to compare how the four different generational groups still living and working together change their views on the topic.

The questionnaire was prepared online and snowball method was used. It was filled in voluntarily and anonymously. Data were collected between December 29, 2018 and March 10, 2019. The questionnaire was completed by 204 respondents. We can say that the number of respondents in the four different groups became almost identical, which meant that the answers were easy to compare.

At the beginning of the questionnaire, we used introductory questions. The next set of questions was already regarding the main topic of emotional intelligence. First of all, we observed the communication link between the employer and the employee. Next, we analysed satisfaction with workplace activities and the importance of work appreciation, that is, verbal praise. We wanted to know the extent to which material assets, professional recognition, development opportunities and a good work environment matter. By completing a web-based (gyorseqtests.hu) emotional intelligence test, we were able to assess the mean value of the subjects' emotional intelligence. At the end of the questionnaire, we inquired about the respondents' demographic data.

During our research we set up 2 hypotheses:

Hypothesis 1: Relationship between age group and perception of emotional intelligence

$\mathrm{H}_{0}$ : There is no relationship between age group and perception of emotional intelligence.

$\mathrm{H}_{1}$ : There is a relationship between age group and perceptions of the importance of emotional intelligence.

Hypothesis 2: The level of emotional intelligence is influenced by age group

$\mathrm{H}_{0}$ : There is no relationship between age group and the level of emotional intelligence.

$\mathrm{H}_{1}$ : There is a relationship between age group and the level of emotional intelligence.

The responses received were aggregated using Microsoft Excel, and the SPSS statistical program was used to test our hypotheses. 


\section{Results}

In this part of the paper, we present the results of a questionnaire research on emotional intelligence. In addition, issues related to emotional intelligence were divided into generational groups. Out of the 204 fillers, $61 \%$ are women and 39\% are men. The fillers were divided into generation groups. This was important, because we wanted to compare how different generations perceive the role of emotional intelligence in the workplace. We used only four generations in the research, because they are currently active in the labor market. $24.5 \%$ of the respondents belong to the Baby Boom, $26 \%$ to the $\mathrm{X}, 25 \%$ to the $\mathrm{Y}$ and $24.5 \%$ to the $\mathrm{Z}$ Generation. We wanted to check how do these values relate to real labor market rates. According to the data [30] we can see that our results relate to real labor market rates.

Table 1

Real labor market rates - employees by age group and generations used in the study (2019/Q3) [30]

\begin{tabular}{|c|c|c|c|}
\hline Generation & Age group & $\begin{array}{c}\text { Number of } \\
\text { employees } \\
\text { (thousand) }\end{array}$ & $\begin{array}{c}\text { Percent of } \\
\text { employees of the } \\
\text { total workforce }\end{array}$ \\
\hline $\mathrm{Z}$ & $15-24$ & 139.8 & $5 \%$ \\
\hline $\mathrm{Y}$ & $25-34$ & 607.3 & $23 \%$ \\
\hline $\mathrm{Y}+\mathrm{X}$ & $35-44$ & 752.9 & $29 \%$ \\
\hline $\mathrm{X}$ & $45-54$ & 635.8 & $25 \%$ \\
\hline $\begin{array}{c}\text { Baby-boom }+ \\
\text { Veteran }\end{array}$ & $55+$ & 449.3 & $17 \%$ \\
\hline & Slovakia & $\mathbf{2 5 8 5 . 1}$ & $\mathbf{1 0 0 \%}$ \\
\hline
\end{tabular}

We also tested the highest level of education. For this question, five options were identified for the respondents. The rate of those with the highest level of education attained a primary school was $2 \%$. They were the least. Secondary education (high school, vocational secondary school and vocational school) was the most marked $(46 \%)$. The proportion of students still in tertiary education is $12 \%$, while $35 \%$ with university degrees. Only $5 \%$ of the respondents indicated that they are postgraduate students.

In terms of occupational status, $2 \%$ of those who filled in said they were owners and $7 \%$ were self-employed. Another $8 \%$ work as managers, while most $(80 \%)$ work as subordinates. The other option was marked by $3 \%$. We also examined the size of the companies they work for. Micro-enterprises are of 38\% (0-9 employees), $28 \%$ of small enterprises (10-49) and $34 \%$ of medium-sized enterprises (50-249). None of our fillers worked for a large company. The duration of the employment relationship was also examined. Only $14 \%$ of those who filled in said they had worked for the company for less than 1 year. 33\% reported 1 to 5 years, and $13 \%$ reported 5 to 10 years. Most fillers (41\%) had been with the same company for more than 10 years. 
In our first hypothesis (Relationship between age group and perception of the importance of emotional intelligence), we made a cross-table. The age group was an ordinal (independent) variable, because we can arrange them in series. To assess the importance of emotional intelligence, however, we used a question in our questionnaire asking our respondents whether emotional or cognitive intelligence they consider more important. This variable is nominal and dependent. Based on our responses, we have obtained the following results.

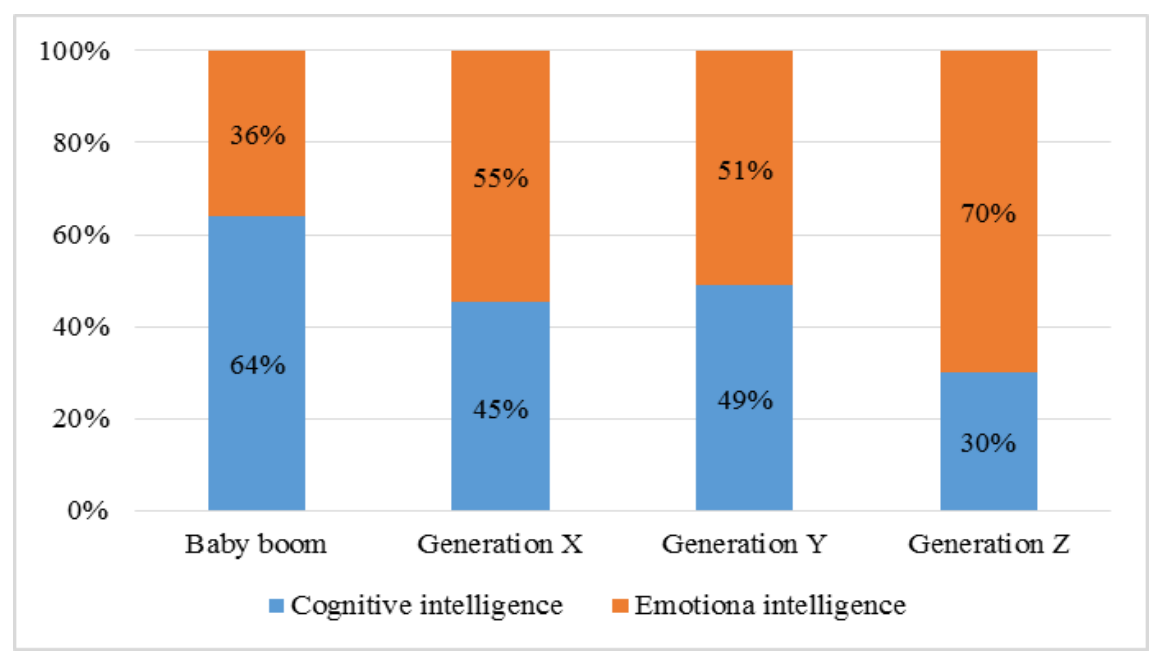

Figure 1

Which intelligence is more important? - By generations

Thus, according to the figure, cognitive intelligence is considered more important by the oldest generation examined, whereas the vast majority of younger ones marked the emotional one. However, in order to prove that our result was not merely a coincidence, we needed further investigation. For this, we performed a Pearson Chi-square test, the results of which are presented in the following table.

Table 2

Contains the result of the $\mathrm{H} 1$ testing

\begin{tabular}{|l|r|r|r|}
\hline & \multicolumn{1}{|c|}{ Value } & df & \multicolumn{1}{|c|}{$\begin{array}{c}\text { Asymp. Sig. } \\
\text { (2-sided) }\end{array}$} \\
\hline Pearson Chi-Square & $11,746^{\text {a }}$ & 3 &, 008 \\
Likelihood Ratio & 11,987 & 3 &, 007 \\
Linear-by-Linear & 9,575 & 1 &, 002 \\
Association & & & \\
N of Valid Cases & 204 & & \\
\hline
\end{tabular}


The degree of freedom in our case was 3, while the significance level was $95 \%$ (0.05). The Chi square value was 11.746 , while the critical value for degree of freedom and significance of 0.05 was 7.815 according to the table. The empirical significance $(\mathrm{P})$ is 0.008 . Thus, overall, the Chi-square we measured is less than critical, and empirical significance is less than significance. Based on these results, we must reject the null hypothesis (no relationship between the two variables) and we have to accept the alternative hypothesis (the relationship between the two variables). Our first hypothesis - the relationship between age group and perception of the importance of emotional intelligence - can be considered as true.

We also made a cross-tabulation of our second hypothesis (the level of emotional intelligence is influenced by age group). The age group was an ordinal (independent) variable because we can arrange them in series. The magnitude of emotional intelligence was examined in 3 categories:

- Low $-0-25$

- Medium - 26-50

- High - 51-75

This variable is also considered to be ordinal, but also dependent. Based on the answers of our respondents, we have obtained the following results.

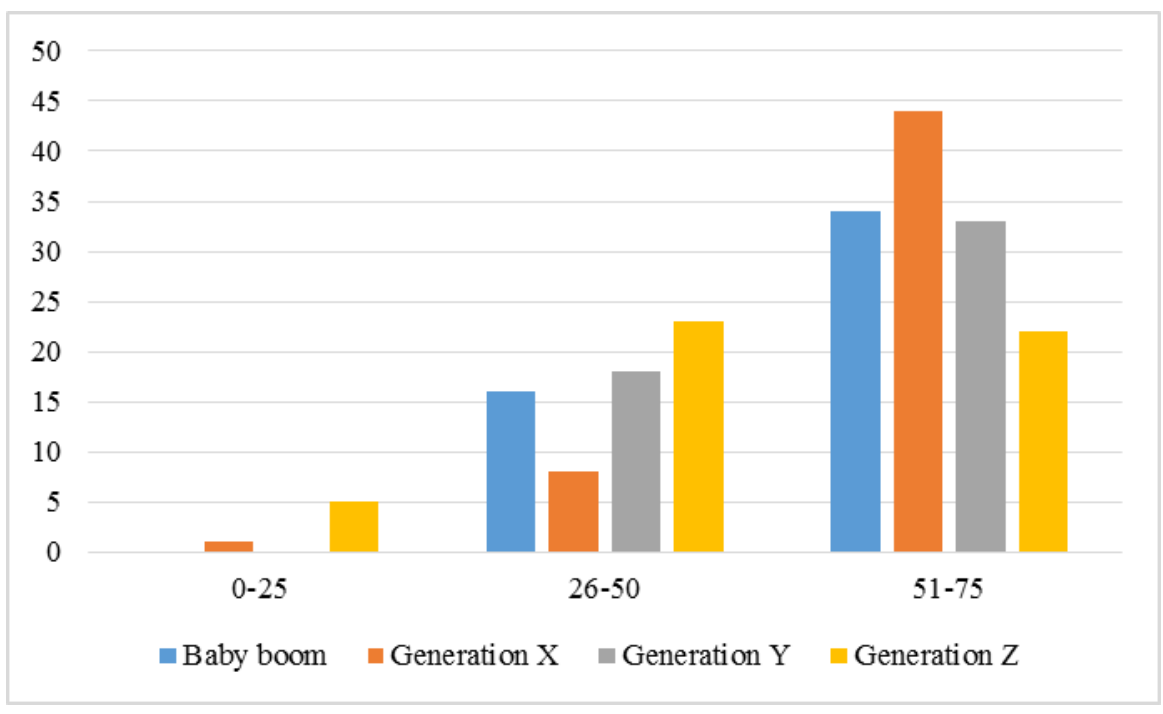

Figure 2

EQ score by generations

According to our results, individuals of Generation $X$ have the highest level of emotional intelligence, while those of Generation $\mathrm{Z}$ have the lowest level of emotional intelligence. However, in order to prove that our result was not merely a 
coincidence, we needed further investigation. This time we wanted to perform the Pearson Chi-square test, but according to the results of the SPSS program, more than $20 \%$ of the cells had values less than 5 . In this sense, we cannot use the Pearson Chi-square test.

Table 3

Contains the result of the $\mathrm{H} 2$ testing

\begin{tabular}{|l|l|r|r|}
\hline & \multicolumn{1}{|c|}{ Value } & df & $\begin{array}{c}\text { Asymp. Sig. } \\
\text { (2-sided) }\end{array}$ \\
\hline Pearson Chi-Square & $25,734^{\mathrm{a}}$ & 6 &, 000 \\
Likelihood Ratio & 26,438 & & 6 \\
Linear-by-Linear & 12,046 & &, 000 \\
Association & & &, 001 \\
N of Valid Cases & 204 & & \\
\hline
\end{tabular}

a. 4 cells $(33,3 \%)$ have expected count less than 5 . The minimum expected count is 1,47

In this case, we need to look at the results of the likelihood ratio. Our significance remained at 0.05 . The significance $(\mathrm{P})$ value we have for the likelihood ratio is 0.000 , which is less than the defined significance. In this case, we must reject the null hypothesis (no relationship between the two variables) and accept the alternative hypothesis (the relationship between the two variables). Our second hypothesis, according to which the level of emotional intelligence is influenced by age, can be considered as true.

\section{Conclusions}

In the first part of our article, we briefly introduced the theory of emotional intelligence. For this we used Hungarian, Slovak and English literature. Emotional intelligence can be found in everyday life such as social contacts. It affects human relationships and leadership activities. It is essential for recognizing, controlling and managing the emotions of ourselves and others. Our emotions affect our environment as they have a profound effect on our emotional development. Environmental influences can guarantee the development of emotional intelligence, for example, the mood in the workplace significantly determines the emotional intelligence of the manager or of subordinates. This intelligence plays an important role in the workplace as it plays a crucial role in communication and in situations that affect behavior and the way people are treated. The closest thing to emotional intelligence is empathy. This allows us to recognize the emotions of others and to be able to gauge their thinking and behavior. In this work we present two aspects of emotional intelligence, its presence in organizations and its measurement, which consists of 16 different steps. We went on to do more with leaders and coaching. In the last subchapter of the theoretical part, we mention the 
6 generational groups, but in our paper we only dealt with 4 generations (Baby Boom, $\mathrm{X}, \mathrm{Y}$ and $\mathrm{Z}$ ), as their members are still active and Already in the job market. For the 4 generations, we have highlighted the most important traits in the workplace. In our research, we identified 2 main hypotheses that examined each generation for emotional intelligence.

Based on our results, both hypotheses were accepted, after confirming the appropriate statistical evidence. Our results indicate that there is a relationship between age group and perceptions of the importance of emotional intelligence, and that the level of emotional intelligence is actually influenced by age group. Furthermore, it has been found that although the youngest (Generation Z) consider emotional intelligence to be more important than cognitive, they still have lower emotional intelligence than their older (Baby Boom, Generation X and Y) counterparts.

\section{Acknowledgement}

This work was supported by the Collegium Talentum 2019/2020 Programme of Hungary.

\section{References}

[1] C. Anyakoha: Job analysis as a tool for improved organizational performance of SMEs in Lagos, Nigeria. Central European Journal of Labour Law and Personnel Management, 2019, Vol. 2, No. 1, pp. 7-16, ISSN 2644-4542, DOI: 10.33382/cejllpm.2019.02.01

[2] B. Arora: Importance of Emotional Intelligence In The Worklpace. International Journal of Engineering and Applied Sciences, 2017, Vol. 4, Iss. 4, pp. 43-45, ISSN: 2394-3661

[3] L. Balázs: Emotional Intelligence, Z-Press Publishing Ltd., 2014, ISBN 9789639493728

[4] A. Bencsik, G. Horváth-Csikós, T. Juhász: Y and Z Generations at Workplaces. Journal of Competitiveness, 2016, Vol. 8, Iss. 3, pp. 90-106, ISSN 1804-1728, DOI: 10.7441/joc.2016.03.06

[5] S. Berkup: Working with generations $\mathrm{X}$ and $\mathrm{Y}$ in generation $\mathrm{Z}$ period: Management of different generations in business life. Mediterranean Journal of Social Sciences, 2014, Vol. 5, No. 19, pp. 218-229, ISSN 20392117, DOI: $10.5901 / \mathrm{mjss} .2014 . v 5 n 19$ p218

[6] K. Buvaneswari: A study of emotional intelligence and work related variables among business executive. EPRA International Journal of Economic and Business Review, 2013, Vol. 1, Iss. 1, pp. 10-21, ISSN 2347-9671

[7] Gy. Csapai, Sz. Berke: Emotional factors influencing managerial growth, In In A. Csata et al. (ed.) $12^{\text {th }}$ Annual International Conference on Economics 
and Business, Editura Risoprint, 2015, pp. 392-398, ISBN 978-973-53$1565-8$

[8] C. Ezigbo: Develop Emotional Intelligence as a MindTool for Leadership Effectiveness and Employee Career Development. Research on Humanities and Social Siences, 2013, Vol. 3, No. 4, pp. 1-9, ISSN 2225-0484

[9] D. Goleman: Working with Emotional Intelligence, Bantam, 2000, ISBN 978-0553378580

[10] D. Goleman: Emotional Intelligence: Why It Can Matter More Than IQ, Bantam, 2005, ISBN 978-0553383713

[11] D. Goleman, R. Boyatzis, A. McKee: Primal Leadership. Unleashing the Power of Emotional Intelligence, Harvard Business Review Press, 2013, ISBN 9781422168035

[12] M. Hitka, S. Lorincová, L. Ližbetinová: Manager's data in human resource management from the perspective of the work position. Acta Oeconomica Universitatis Selye, 2017, Vol. 6, No. 2, pp. 69-80, ISSN 1338-6581

[13] M. Hitka, S. Lorincova, G. P. Bartakova, L. Lizbetinova, P. Starchon, C. Li, E. Zaborova, T. Markova, J. Schmidtova, L. Mura: Strategic Tool of Human Resource Management for Operation of SMEs in the Woodprocessing Industry. Bioresources, 2018, Vol. 13, No. 2, pp. 2759-2774, ISSN: 1930-2126

[14] D. L. Joseph, D. A. Newman: Emotional intelligence: An integrative metaanalysis and cascading model, Journal of Applied Psychology, 2010, Vol. 95, No. 1, pp. 54-78, ISSN 0021-9010, DOI: 10.1037/a0017286

[15] D. Kannaiah, R. Shanthi: A Study on Emotional Intelligence at Work Place. European Journal of Business and Management, 2018, Vol. 7, No. 24, pp. 147-154, ISSN 2222-2839

[16] A. Kolnhofer-Derecskei, R. Zs. Reicher, Á. Szeghegyi: Transport Habits and Preferences of Generations - Does it Matter, Regarding the State of The Art? Acta Polytechnica Hungarica, 2019, Vol. 16, No. 1, pp. 29-44, ISSN 1785-8860, DOI: 10.12700/APH.16.1.2019.1.2

[17] K. Lazanyi, M. Fulop: Why don't we trust others? Acta Oeconomica Universitatis Selye, 2017, Vol. 6, No. 1, pp. 61-70, ISSN 1338-6581

[18] S. Lorincová: Human resource and corporate culture: Gender-based differences in the assessment. Central European Journal of Labour Law and Personnel Management, 2018, Vol. 1, No. 1, pp. 28-45, ISSN 2644-4542, DOI: 10.33382/cejllpm.2018.01.03

[19] J. D. Mayer, R. D. Roberts, S. G. Barsade: Human Abilities: Emotional Intelligence, Annual Review of Psychology, 2008, Vol. 59, No. 1, pp. 507536, ISSN 1545-2085, DOI:10.1146/annurev.psych.59.103006.093646 
[20] M. McCrindle: The ABC of XYZ: Understanding the Global Generations, Australia, McCrindle Research Pty Ltd, 2014, ISBN 978-1742230351

[21] M. Minárová: Managers in SMEs and their emotional abilities. Acta Oeconomica Universitatis Selye, 2015, Vol. 4, No. 1, pp. 83-92, ISSN $1338-6581$

[22] L. Mura: Current situation in Family Businesses. Managerial trends in the development of enterprises in globalization era, 2017, pp. 178-185, ISBN 978-80-552-1739-0

[23] L. Mura, A. Ključnikov, M. Tvaronavičiene, A. Androniceanu: Development Trends in Human Resource Management in Small and Medium Enterprises in the Visegrad Group. Acta Polytechnica Hungarica, 2017, Vol. 14, No. 7, pp. 105-122, ISSN 1785-8860, DOI: 10.12700/APH.14.7.2017.7.7

[24] S. Neale, L. Spencer-Arnell, L. Wilson: Emotional intelligence coaching, Kogan Page, 2009, ISBN 978-0749463564

[25] J. Palfrey, U. Gasser: Born digital: Understanding the first generation or digital natives, Basic Books, 2010, ISBN 978-0465018567

[26] J. Poór: Internationalization and Globalization in Human Resource Management, CompLex Publishing, 2013, ISBN 9789632952871

[27] S. Saini: Emotional Intelligence at Workplace - A Conceptual Study. In International Journal of Management Studies, 2018, Vol. 5, Iss. 3, pp. 5356, ISSN 2231-2528, DOI: 10.18843/ijms/v5i3(5)/08

[28] P. Salovey, J. D. Mayer: Emotional Intelligence, Imagination, Cognition and Personality, 1990, Vol. 9, No. 3, pp. 185-211, ISSN 0276-2366, DOI:10.2190/dugg-p24e-52wk-6cdg

[29] N. S. Schutte, J. M. Malouff, L. E. Hall, D. J. Haggerty, J. T. Cooper, C. J. Golden, L. Dornheim: Development and validation of a measure of emotional intelligence, Personality and Individual Differences, 1998, Vol. 25, No. 2, pp. 167-177, ISSN 0191-8869, DOI: 10.1016/S01918869(98)00001-4

[30] Slovstat: Employees by age group, Available on <http://datacube.statistics.sk/\#!/view/sk/VBD_SK_WIN/pr3115qr/v_pr311 5qr_00_00_00_sk>, [accessed 09.03.2020]

[31] G. Statnickè, R. Jegelavičiūte: Influence of teaching methods on the selfleadership expression of the millenium generation students. Acta Oeconomica Universitatis Selye, 2017, Vol. 6, No. 1, pp. 137-154, ISSN $1338-6581$

[32] A. Szabó, B. Kun., R. Urbán, Zs. Demetrovics: Initial results on the domestic application of the wong and law emotional intelligence scale 
(wleis-hu), Mental Hygiene and Psychomatics,2011, Vol. 12, No. 1, pp. 115, ISSN 1419-8126, DOI: 10.1556/Mental.12.2011.1.1

[33] G. Szabó-Szentgróti, M. Gelencsér, E. Szabó-Szentgróti, Sz. Berke: Generational impact in workplace conflicts, Leadership science, 2019, Vol. 50, No. 4, pp. 77-88, ISSN 0133-0179, DOI: 10.14267/VEZTUD.2019.04.08

[34] D. Tapscott: Grown up digital. How the net generation is changing your world, McGraw-Hill, 2009, ISBN 978-0071508636

[35] A. Tari: Generation Y, Jaffa Publishing Ltd., 2010, ISBN 9789639971202

[36] A. Tari: Generation Z, Tericum Publishing Ltd., 2011, ISBN 9789639633926

[37] M. Vágnerová: Basics of psychology, Karolinum, 2005, ISBN 978-80-2460841-9

[38] D. Vlacseková: Comparative analysis of motivation of civil servants and public servants in the local state administration - case study of Slovakia. In: Central European Journal of Labour Law and Personnel Management, 2019, Vol. 2, No. 1, pp. 74-93, ISSN 2644-4542, DOI: 10.33382/cejllpm.2019.02.06

[39] J. Whitmore: Coaching for Performance. The Principles and Practice of Coaching and Leadership, Nicholas Brealey Publishing, 2017, ISBN 9781473658127

[40] R. Zemke, C. Raines, B. Filipczak: Generations at Work: Managing the Clash of Veterans, Boomers, Xers and Nexters in Your Workplace, Amacom, 2000, ISBN 978-0814404805

[41] J. Žul'ová, M. Švec, A. Madleňák: Personality aspects of the employee and their exploration from the GDPR perspective. In: Central European Journal of Labour Law and Personnel Management, 2018, Vol. 1, No. 1, pp. 68-77, ISSN 2644-4542, DOI: 10.33382/cejllpm.2018.01.05 